\title{
QUICK ASSESSMENT METHOD FOR CANISTER STRUCTURAL DESIGN OF INA-CBT
}

\section{METODE KAJI CEPAT PADA DESAIN STRUKTUR CANISTER INA-CBT}

\author{
Mulyo Harris Pradono ${ }^{1}$ \\ ${ }^{1}$ Pusat Teknologi Reduksi Risiko Bencana, Kedeputian Bidang Teknologi Pengembangan \\ Sumberdaya Alam, Badan Pengkajian dan Penerapan Teknologi, Gedung 820, Geostech, Kawasan \\ PUSPIPTEK, Serpong, Tangerang 15314, telepon: (021) 75791378 \\ e-mail: mulyo.harris@bppt.go.id
}

\begin{abstract}
Canister in the Ina-CBT (Indonesian Cable-Based Tsunameter) system is a structure to protect underwater sensor system. Canister and sensor system form the OBU (Ocean Bottom Unit) system. This OBU is connected by land via submarine cable. This canister is used to protect the sensor system from the underwater leakage and water pressure. Because the location of the OBU can usually reach a depth of thousands of meters in the sea, the water pressure on the OBU becomes very large. As an illustration, for a depth of 1000 meters, the pressure on the canister wall is 1 ton per square meter. For this reason, a strong canister structure is needed to withstand water pressure without damage. The strength of this structure can be analyzed using a structural analysis program. However, if a change in pressure and dimension is needed, it needs to be re-modeled to determine its strength which requires time. Therefore a study of a method to determine quickly the strength of the canister is carried out. The results show that this method is very useful to quickly determine the dimensions and initial weight of the canister due to the external pressure load of sea water. For example, with SS 316 L stainless steel material and a canister inner radius of $100 \mathrm{~mm}$, the canister is suitable for further design only for external pressures up to $30 \mathrm{MPa}$. For pressures above $30 \mathrm{MPa}$, the thickness and weight of the canisters are becoming impractical for onboard handling.
\end{abstract}

Keywords: canister, ina-cbt, strength, water pressure, quick method.

\begin{abstract}
Abstrak
Canister di dalam sistem Ina-CBT (Indonesian Cable-Based Tsunameter) merupakan struktur pelindung bagi sistem sensor bawah laut. Keduanya membentuk sistem OBU (Ocean Bottom Unit). OBU ini dihubungkan dengan daratan melalui kabel bawah laut (submarine cable). Canister ini gunanya untuk melindungi sistem sensor dari kebocoran dan tekanan air bawah laut. Karena letak OBU biasanya bisa sampai kedalaman ribuan meter di dalam laut, maka tekanan air pada OBU menjadi sangat besar. Sebagai gambaran, untuk kedalaman 1000 meter, maka tekanan di dinding canister adalah 1 ton per meter persegi. Untuk itu diperlukan struktur canister yang kuat menahan tekanan air tanpa terjadi kerusakan. Kekuatan struktur ini dapat dianalisis dengan menggunakan program analisis struktur. Akan tetapi, jika diperlukan perubahan variabel tekanan dan dimensi, maka perlu dilakukan pemodelan ulang yang memerlukan waktu untuk mengetahui kekuatannya. Oleh sebab itu dilakukan kajian terhadap suatu metode pemeriksaan cepat untuk mengetahui kekuatan canister. Hasilnya menunjukkan bahwa metode ini sangat berguna untuk mengetahui secara cepat dimensi dan berat awal canister akibat beban tekanan luar dari air laut. Misalnya, dengan material baja antikarat SS $316 \mathrm{~L}$ dan jari-jari dalam canister sebesar $100 \mathrm{~mm}$, maka canister layak desain lebih lanjut hanya untuk tekanan luar sampai dengan $30 \mathrm{MPa}$ saja. Untuk tekanan di atas $30 \mathrm{MPa}$, maka tebal dan berat canister menjadi terlalu besar dan tidak mudah saat penggelaran.
\end{abstract}

Kata kunci: canister, ina-cbt, kekuatan, tekanan air, metode cepat. 


\section{PENDAhULUAN}

\subsection{Latar Belakang}

Indonesian Tsunami Early Warning System (InaTEWS) merupakan sistem peringatan dini untuk bencana tsunami, baik yang disebabkan oleh gempa maupun lainnya (BPPT, 2019b). Teknologi ini sedang dikembangkan oleh BPPT dalam rangka membantu masyarakat dan stakeholder lainnya yang terkait (BNPB, BMKG, Pemda, dan lainnya). BPPT sebagai lembaga yang bergerak di bidang pengkajian dan penerapan teknologi mendapatkan amanah melalui Peraturan Presiden nomor 93 tahun 2019 tentang Penguatan dan Pengembangan Sistem Informasi Gempa Bumi dan Peringatan Dini Tsunami (KemenkumHAM, 2019).

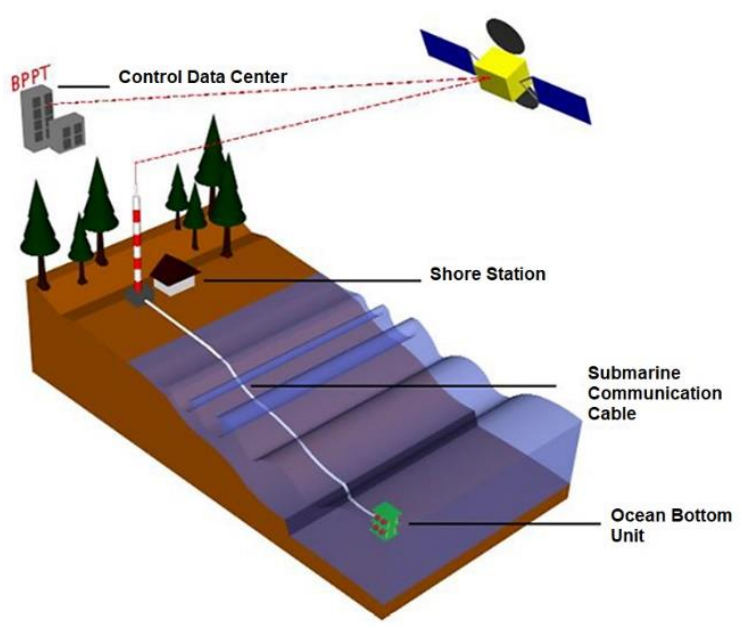

Gambar 1. Konfigurasi Sistem Indonesian Cable Based Tsunameter (Ina-CBT) (BPPT, 2019a)

Sistem Indonesian Cable Based Tsunameter (Ina-CBT) mempunyai konfigurasi seperti ditunjukkan pada Gambar 1. Dalam konfigurasi ini, sensor Ocean Bottom Unit (OBU) dihubungkan secara langsung ke stasiun pantai (shore station) menggunakan kabel serat optik dasar laut. Di stasiun pantai, data disimpan dan diproses, selanjutnya secara otomatis dikirimkan via satelit komunikasi Inmarsat atau Iridium ke RDS (Read Down Station atau Control Data Center) di BPPT setiap perioda waktu yang telah ditentukan (BPPT, 2019a). Dalam kondisi normal, stasiun pantai CBT mengirimkan data setiap perioda waktu 1 jam. Dalam kondisi mode tsunami, perioda pengiriman data diperpendek menjadi setiap 1 menit. Karena CBT mempunyai stasiun pantai maka data yang dikirim bisa jauh lebih banyak dibanding sistem buoy. Hal ini dikarenakan media komunikasi yang digunakan bisa berbeda dari media satelit pada buoy (tidak ada opsi lain). Pada CBT bisa digunakan modem GSM yang jauh lebih murah (per volume data) dibanding satelit.

Sistem teknologi deteksi tsunami dengan teknologi ini sudah dipersiapkan oleh BPPT dan digelar di tahun 2019. Perubahan signifikan ada pada panjang kabel, penambahan sensor akselerometer, redundansi sistem pengiriman data (dengan menambahkan teknologi radiolink untuk remote area), penambahan CCTV, serta modifikasi OBU yang lebih handal.

Komponen Ina-CBT yang berperan sebagai ujung tombak dalam mendeteksi tsunami adalah Ocean Bottom Unit (OBU). Di dalam OBU terdapat sensor pengukur tekanan air dan sensor-sensor lainnya (misalnya akselerometer dan seismometer). Sensorsensor ini dan peralatan elektroniknya berada dalam wadah pelindung yang dinamakan canister (atau enclosure). Wadah ini berfungsi untuk melindungi komponen di dalamnya dari tekanan air (hingga kedalaman ribuan meter) dan dari kebocoran. Untuk itu, diperlukan struktur canister yang kuat, kedap, dan tahan lama.

Dengan menempatkan sistem OBU di dasar laut dengan kedalaman sampai dengan 3883 meter (BPPT, 2020a), maka tekanan yang dialami sistem OBU akan sangat besar. Sebagai gambaran, pada kedalaman 3883 meter, maka tekanan yang dialami permukaan permukaan OBU adalah sekitar 388 bar, atau setara dengan $388 \mathrm{~kg}$ per sentimeter persegi permukaan.

Tegangan yang terjadi pada canister akibat tekanan ini bergantung kepada bentuknya. Metoda untuk mengetahui tegangannya adalah dengan analisis numerik untuk bentuk-bentuk canister yang tidak beraturan. Untuk bentuk-bentuk yang beraturan, banyak metode persamaan matematik yang dapat digunakan (The Engineering Toolbox, 2020). Sedangkan untuk bentuk-bentuk yang tidak beraturan, metode numerik dengan memanfaatkan metoda elemen hingga dapat menggunakan program analisis struktur, misalnya SAP 2000 (Computers and Structures, 2014), Ansys (Ansys, 2020) dan lain-lainnya.

Bentuk canister ada bagian yang beraturan, yaitu silinder tengah dari canister. Gambar 2 menunjukkan gambar canister yang didesain di BPPT. Bagian silinder mempunyai bentuk beraturan, akan tetapi mempunyai fungsi yang sangat penting yaitu menjaga komponen di dalam canister agar terlindungi dari tekanan air laut. 


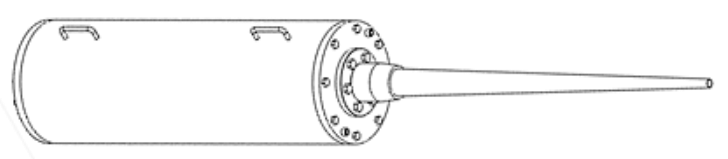

Gambar 2. Canister (atau Enclosure) sebagai pelindung komponen elektronik OBU (BPPT, 2020b)

Makalah ini akan membahas kajian mengenai metode untuk mengetahui kekuatan canister secara cepat. Dengan mengetahui kekuatan dan dimensi canister secara cepat, maka keputusan-keputusan yang diperlukan untuk menentukan dimensi awal dan material canister menjadi lebih mudah.

\subsection{Tujuan Penelitian}

Tujuan dari penelitian ini adalah untuk mengkaji pentingnya sebuah metoda untuk memberikan gambaran awal dari dimensi dan berat canister, untuk membantu pihak-pihak terkait dengan cepat memutuskan jenis dan material canister.

\section{BAHAN DAN METODE}

\subsection{Bahan}

Bahan yang digunakan dalam penelitian ini adalah sebuah desain canister yang didesain di BPPT untuk menunjang kegiatan Indonesian Tsunami Early Warning System (InaTEWS) yang merupakan sistem peringatan dini untuk bencana tsunami, baik yang disebabkan oleh gempa maupun sumber lainnya. Gambar 2 di atas menunjukkan tampak luar dari canister. Gambar 3 menunjukkan irisan memanjang dari canister tersebut.

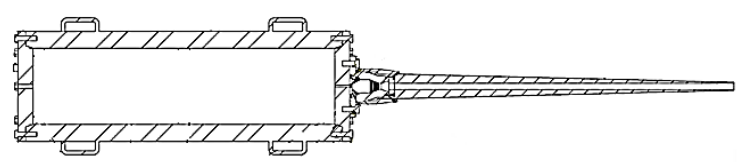

Gambar 3. Potongan memanjang dari Canister di Gambar 2 (BPPT, 2020b)

Silinder yang ada di sebelah kiri gambar mempunyai dimensi diameter dalam (inner diameter) sebesar $200 \mathrm{~mm}$ dan diameter luar (outer diameter) sebesar $290 \mathrm{~mm}$. Tebal dari dinding silinder canister ini adalah $45 \mathrm{~mm}$. Canister ini untuk ditempatkan di kedalaman laut sedalam $3000 \mathrm{~m}$. Dengan kedalaman tersebut, maka tekanan di dinding canister adalah 300 bar (30 MPa).

\subsection{Metode}

Metode yang digunakan adalah:

a. Penelusuran rumus matematis tegangan pada silinder akibat tekanan luar (outer pressure).

b. Pembuatan tabel perhitungan hubungan antara tekanan luar, dimensi silinder, tebal silinder, tegangan, material, dan berat.

c. Pengumpulan data dimensi peralatan elektronik OBU di dalam canister.

d. Pengumpulan data mekanis dari material baja SS $316 \mathrm{~L}$ dan Titanium Grade 5.

e. Pemodelan silinder menggunakan program analisis struktur untuk mengetahui deformasi silinder dan distribusi tegangan dalam dinding silinder akibat tekanan luar.

\section{HASIL DAN PEMBAHASAN}

\subsection{Model Matematis}

Ketika sebuah tabung silinder dikenai beban tekanan dari dalam atau dari luar, maka terjadi tegangan arah keliling, arah radial, dan arah longitudinal (memanjang). Gambar 4 menunjukkan ilustrasi tegangan pada dinding silinder berdinding tebal (kasus pada dinding canister).

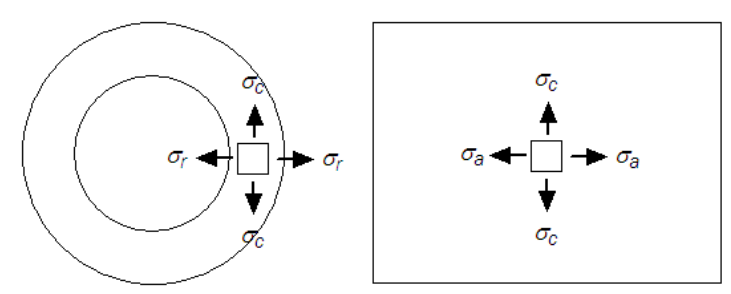

Gambar 4. Pola tegangan yang terjadi pada silinder berdinding tebal akibat tekanan luar atau dalam (The Engineering Toolbox, 2020)

Tegangan yang diperlukan nilainya dalam menentukan kekuatan adalah yang arah keliling yaitu $\sigma_{c}$ karena tegangan ini yang besar nilainya. Tegangan ini juga dinamakan Hoop Stress. Tegangan ini pada suatu titik di dalam tabung silinder dapat dinyatakan pada Persamaan (1). Untuk kasus yang terjadi di canister, tekanan hanya dari luar. Maka rumus ditunjukkan di persamaan (2). Sebagai catatan, tegangan tertinggi di dinding adalah saat $r=r_{i}$ (di dinding bagian dalam silinder).

$$
\begin{aligned}
\sigma_{c} & =\frac{p_{i} r_{i}^{2}-p_{o} r_{o}^{2}}{r_{o}^{2}-r_{i}^{2}}-\frac{r_{i}^{2} r_{o}^{2}\left(p_{o}-p_{i}\right)}{r^{2}\left(r_{o}^{2}-r_{i}^{2}\right)} \\
\sigma_{c} & =\frac{p_{o} r_{o}^{2}}{r_{o}^{2}-r_{i}^{2}}-\frac{r_{i}^{2} r_{o}^{2} p_{o}}{r^{2}\left(r_{o}^{2}-r_{i}^{2}\right)}
\end{aligned}
$$


- $\sigma_{c}$ adalah tegangan arah melingkar di dalam silinder (MPa)

- $p_{i}$ adalah tekanan dari dalam silinder (MPa)

- $p_{o}$ adalah tekanan dari luar silinder (MPa)

- $r_{i}$ adalah jari-jari dalam silinder $(\mathrm{mm})$

- $r_{o}$ adalah jari-jari luar silinder (mm)

- $r$ adalah jari-jari sampai ke titik kajian dalam silinder $(\mathrm{mm})\left(r_{i}<r<r_{0}\right)$

Berdasarkan rumus di atas maka dibuat tabel dan grafik untuk berbagai tekanan dan tebal silinder. Untuk dimensi dasar silinder yaitu diameter rongga dalam (inner diameter) dan panjang rongga silinder ditentukan berdasarkan dimensi riil peralatan elektronik yang akan dipasang di dalam silinder, yaitu diameter dalam $200 \mathrm{~mm}$ dan panjang $800 \mathrm{~mm}$ (BPPT, 2020b).

\subsubsection{Material Baja Antikarat (SS 316 L)}

Material baja antikarat SS316L banyak digunakan sebagai material canister karena mempunyai kekuatan mekanis yang baik dan kemampuan tahan karat yang cukup. Material ini mempunyai sifat fisik dan mekanik seperti ditunjukkan pada Tabel 1. Data tersebut digunakan untuk menganalisis kekuatan, deformasi, dan berat canister. Analisis kekuatan dan berat canister dilakukan di subbab ini, sedangkan analisis deformasi dilakukan di sub-bab 3.2 karena menggunakan analisis numerik.

Tabel 1. Sifat Fisik dan Mekanik Baja Antikarat (ASTM International, 2015)

\begin{tabular}{c|l|c}
\hline No & Sifat Fisik dan Mekanik & Nilai dan Unit \\
\hline 1 & Massa jenis & $8 \mathrm{gram} / \mathrm{cm}^{3}$ \\
\hline 2 & Kuat tarik (leleh/luluh) & $200 \mathrm{MPa}$ \\
\hline 3 & Modulus elastisitas & $193 \mathrm{GPa}$ \\
\hline 4 & Poisson ratio & 0,27 \\
\hline
\end{tabular}

Analisis kekuatan dan berat canister dilakukan dengan variabel berupa tekanan luar $\left(p_{o}\right)$ yang dimulai dari $5 \mathrm{MPa}$ sampai dengan $60 \mathrm{MPa}$, di mana ini setara dengan tekanan air pada kedalaman 500 sampai dengan 6000 meter. Jari-jari dalam silinder $\left(r_{i}\right)$ adalah konstan $100 \mathrm{~mm}$. Nilai yang diinput adalah ketebalan dinding silinder $(t)$ agar memberikan tegangan dinding bagian dalam $(s-h o o p-i)$ berada pada sekitar $134 \mathrm{MPa}$. Nilai ini adalah $2 / 3$ dari kuat tarik leleh baja yang sebesar $200 \mathrm{MPa}$ (BPPT, 2020b). Jari-jari luar silinder $\left(r_{o}\right)$ adalah jari-jari $\left(r_{i}\right)$ dalam ditambah tebal silinder $(t)$. Berat canister dihitung sebagai volume silinder tersebut dengan panjang $800 \mathrm{~mm}$ ditambah berat tutup pada ujung-ujung silinder. Diameter tutup sama dengan diameter luar silinder, dan tebalnya sama dengan tebal silinder. Untuk berat komponen di luar silinder, seperti cone (tempat masuknya kabel bawah laut), maka berat ditambah $15 \%$ menjadi berat total $\left(W_{\text {plus }}\right)$. Berat jenis material baja antikarat ini adalah $8 \mathrm{gram} / \mathrm{cm}^{3}$ (Badan Standardisasi Nasional, 2012). Hasilnya ditunjukkan pada Tabel 2. Kurva hubungan antara tekanan luar dengan tebal dan berat canister ditunjukkan pada Gambar 5.

Tabel 2. Perhitungan dimensi dan berat canister dengan material baja antikarat

\begin{tabular}{|c|c|c|c|c|c|c|}
\hline No & $\begin{array}{c}\mathrm{po} \\
(\mathrm{MPa})\end{array}$ & $\begin{array}{c}\mathrm{ri} \\
(\mathrm{mm})\end{array}$ & $\begin{array}{c}\text { ro } \\
(\mathrm{mm})\end{array}$ & $\stackrel{\mathrm{t}}{(\mathrm{mm})}$ & $\begin{array}{c}\text { s- } \\
\text { hoop-i } \\
\text { (MPa) }\end{array}$ & $\begin{array}{c}\text { W plus } \\
(\mathrm{kg})\end{array}$ \\
\hline 1 & 5 & 100 & 104 & 4 & -133 & 20 \\
\hline 2 & 10 & 100 & 108.5 & 8.5 & -133 & 44 \\
\hline 3 & 15 & 100 & 113.5 & 13.5 & -134 & 72 \\
\hline 4 & 20 & 100 & 119.4 & 19.4 & -134 & 106 \\
\hline 5 & 25 & 100 & 126 & 26 & -135 & 148 \\
\hline 6 & 30 & 100 & 134 & 34 & -135 & 202 \\
\hline 7 & 35 & 100 & 144 & 44 & -135 & 274 \\
\hline 8 & 40 & 100 & 157 & 58 & -135 & 379 \\
\hline 9 & 45 & 100 & 173 & 73 & -135 & 524 \\
\hline 10 & 50 & 100 & 196 & 96 & -135 & 763 \\
\hline 11 & 55 & 100 & 238 & 138 & -134 & 1304 \\
\hline 12 & 60 & 100 & 312 & 212 & -134 & 2615 \\
\hline
\end{tabular}

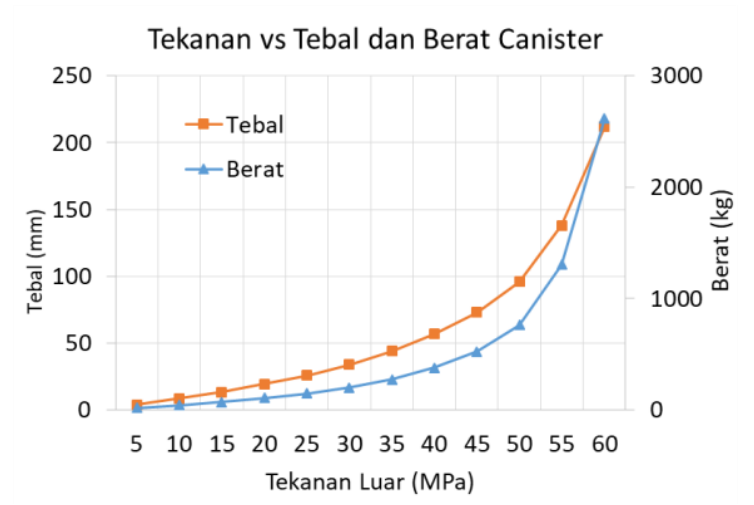

Gambar 5. Kurva hubungan antara Tekanan Luar dengan Tebal dan Berat Canister (Baja SS 316 L)

Jika diperhatikan nilai tebal dan berat canister tersebut, maka pada nilai-nilai tekanan luar yang rendah (antara $5 \mathrm{MPa}$ sampai dengan $30 \mathrm{MPa}$ ), maka tebal dan berat canister masih dalam batas yang proporsional, yaitu tebal antara $4 \mathrm{~mm}$ sampai dengan $34 \mathrm{~mm}$. Nilai ini jika dibandingkan dengan diameter dalam canister sebesar 200 $\mathrm{mm}$, maka masih proporsional. Beratnya juga berada antara $20 \mathrm{~kg}$ sampai dengan $202 \mathrm{~kg}$. Akan tetapi, jika diberikan tekanan yang lebih tinggi, mulai dari $35 \mathrm{MPa}$ sampai dengan 60 MPa, maka tebalnya menjadi tidak proporsional. Tebal canister menjadi $44 \mathrm{~mm}$ sampai dengan $212 \mathrm{~mm}$ dan beratnya antara $274 \mathrm{~kg}$ sampai dengan $2615 \mathrm{~kg}$. Pada kasus ini tebal canister dapat melebihi jari-jari dalam canister sebesar $100 \mathrm{~mm}$. Beratnya juga 
menjadi sangat besar sehingga akan menyulitkan dalam operasi pemindahan dan peletakan.

Dari hasil di atas, maka dapat disimpulkan bahwa dengan material SS $316 \mathrm{~L}$ dan dengan dimensi di atas, maka canister perlu didesain secara detil untuk tekanan luar sampai dengan $30 \mathrm{MPa}$ saja (setara dengan kedalaman air 3000 meter). Untuk kedalaman lebih dari 3000 meter, maka perlu ditinjau penggunaan material lain, misalkan Titanium.

\subsubsection{Material Titanium (Ti-6Al-4V)}

Material Titanium yang akan digunakan adalah jenis Ti-6Al-4V atau material Titanium Grade 5. Material ini mempunyai sifat fisik dan menkanis yang sangat baik sehingga banyak digunakan dalam komponen struktur yang sangat penting. Hanya saja workability dari material ini rendah. Artinya pembentukan material ini menjadi produk tidak mudah. Sehingga di Indonesia belum banyak penggunaan material ini untuk bentuk yang besar (BPPT, 2020b). Sifat fisik dan mekanik dari material Ti-6Al-4V ditunjukkan pada Tabel 3.

Tabel 3. Sifat Fisik dan Mekanik Titanium Ti-6Al4V (Grade 5) (BPPT, 2020b)

\begin{tabular}{c|l|c}
\hline No & Sifat Fisik dan Mekanik & Nilai dan Unit \\
\hline 1 & Massa jenis & $4.5 \mathrm{gram} / \mathrm{cm}^{3}$ \\
\hline 2 & Kuat tarik (leleh/luluh) & $1100 \mathrm{MPa}$ \\
\hline 3 & Modulus elastisitas & $114 \mathrm{GPa}$ \\
\hline 4 & Poisson ratio & 0,33 \\
\hline
\end{tabular}

Berdasarkan tabel di atas, maka tampak keunggulan sifat fisik dan mekanik dari material Titanium ini dibanding dengan material baja antikarat di atas. Material Titanium mempunyai berat hampir setengah dari material baja dan mempunyai kuat tarik lima kali lebih besar.

Berikut adalah perhitungan kekuatan dan berat canister dengan variabel berupa tekanan luar $\left(p_{o}\right)$ yang dimulai dari $30 \mathrm{MPa}$ sampai dengan $60 \mathrm{MPa}$ dan jari-jari dalam silinder $\left(r_{i}\right)$ adalah konstan $100 \mathrm{~mm}$. Nilai yang diinput adalah ketebalan dinding silinder $(t)$ agar memberikan tegangan dinding bagian dalam (s-hoop-l) berada pada sekitar $440 \mathrm{MPa}$. Nilai ini adalah 1/2 dari kuat tarik leleh Titanium yang sebesar $1100 \mathrm{MPa}$ (BPPT, 2020b). Berat canister dihitung sebagai volume silinder tersebut dengan panjang $800 \mathrm{~mm}$ ditambah berat tutup pada ujung-ujung silinder. Diameter tutup sama dengan diameter luar silinder, dan tebalnya sama dengan tebal silinder. Untuk berat komponen di luar silinder, seperti cone (tempat masuknya kabel bawah laut), maka berat ditambah $15 \%$ menjadi berat total $\left(W_{\text {plus }}\right)$. Berat jenis material Titanium ini adalah 4,5 $\mathrm{gram} / \mathrm{cm}^{3}$. Hasilnya ditunjukkan pada Tabel 4. Kurva hubungan antara tekanan luar dengan tebal dan berat canister ditunjukkan pada Gambar 6.

Tabel 4. Perhitungan dimensi dan berat canister dengan material Titanium

\begin{tabular}{r|r|r|r|r|r|r}
\hline No & $\begin{array}{c}\text { po } \\
(\mathrm{MPa})\end{array}$ & $\begin{array}{c}\mathrm{ri} \\
(\mathrm{mm})\end{array}$ & $\begin{array}{c}\text { ro } \\
(\mathrm{mm})\end{array}$ & $\begin{array}{c}\mathrm{t} \\
(\mathrm{mm})\end{array}$ & $\begin{array}{c}\text { s-hoop-i } \\
(\mathrm{MPa})\end{array}$ & $\begin{array}{c}\mathrm{W} \\
\text { plus } \\
(\mathrm{kg})\end{array}$ \\
\hline 1 & 30 & 100 & 107.6 & 7.6 & -440 & 22 \\
\hline 2 & 35 & 100 & 109 & 9 & -442 & 26 \\
\hline 3 & 40 & 100 & 110.5 & 10.5 & -442 & 31 \\
\hline 4 & 45 & 100 & 112.1 & 12.1 & -441 & 36 \\
\hline 5 & 50 & 100 & 113.7 & 13.7 & -442 & 41 \\
\hline 6 & 55 & 100 & 115.4 & 15.4 & -442 & 46 \\
\hline 7 & 60 & 100 & 117.2 & 17.2 & -441 & 52 \\
\hline
\end{tabular}

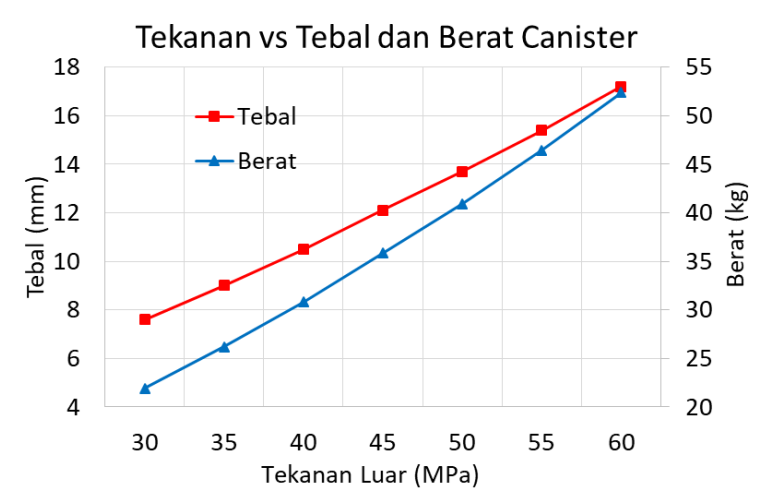

Gambar 6. Kurva hubungan antara Tekanan Luar dengan Tebal dan Berat Canister (Titanium Ti-6Al-4V)

Jika dilihat pada kurva di atas, maka pada nilai tekanan antara $30 \mathrm{MPa}$ sampai dengan $60 \mathrm{MPa}$, maka kurva masih mendekati garis lurus. Artinya penambahan tekanan masih proporsional dengan penambahan dimensi dan berat canister. Nilai tebal dan beratnya pun masih dalam batas wajar dalam pembuatan canister, yaitu tebal $7,6 \mathrm{~mm}$ sampai dengan $17,2 \mathrm{~mm}$, dan beratnya antara $22 \mathrm{~kg}$ sampai dengan $52 \mathrm{~kg}$.

Dari hasil di atas, maka dapat disimpulkan bahwa dengan material Titanium maka didapat dimensi dan berat canister yang jauh lebih kecil dibanding dengan material baja antikarat. Hanya saja, kemampuan produksi canister di Indonesia masih perlu dikaji lebih lanjut, mengingat sangat rendahnya workability dari material Titanium ini.

\subsection{Perubahan Dimensi Dalam}

Mengingat di lapangan akan diletakkan canister pada kedalaman yang hampir mencapai 4000 meter, maka akan dikaji jarijari dalam berapa yang dapat diterima untuk pembuatan canister bermaterial baja antikarat untuk kedalaman sampai dengan 4000 meter 
(tekanan $40 \mathrm{MPa}$ ). Tabel 5 berikut menunjukkan nilai tekanan $40 \mathrm{MPa}$ yang diterapkan pada canister dengan jari-jari 100 $\mathrm{mm}$ diperkecil sampai dengan $70 \mathrm{~mm}$, untuk mengetahui pengaruhnya pada tebal dan berat canister. Kurva hubungan antara jari-jari dalam canister dengan tebal dan berat ditunjukkan pada Gambar 7.

Tabel 4. Hubungan antara jari-jari dalam canister dengan tebal dan berat

\begin{tabular}{c|r|r|r|r|r|r}
\hline No & $\begin{array}{c}\mathrm{po} \\
(\mathrm{MPa})\end{array}$ & $\begin{array}{c}\mathrm{ri} \\
(\mathrm{mm})\end{array}$ & $\begin{array}{c}\mathrm{ro} \\
(\mathrm{mm})\end{array}$ & $\begin{array}{c}\mathrm{t} \\
(\mathrm{mm})\end{array}$ & $\begin{array}{c}\text { s-hoop-i } \\
(\mathrm{MPa})\end{array}$ & $\begin{array}{c}\mathrm{W} \\
\text { plus } \\
(\mathrm{kg})\end{array}$ \\
\hline 1 & 40 & 100 & 158 & 58 & -133 & 388 \\
\hline 2 & 40 & 95 & 150 & 55 & -134 & 347 \\
\hline 3 & 40 & 90 & 142 & 52 & -134 & 309 \\
\hline 4 & 40 & 85 & 134 & 49 & -134 & 273 \\
\hline 5 & 40 & 80 & 126 & 46 & -134 & 240 \\
\hline 6 & 40 & 75 & 118 & 43 & -134 & 209 \\
\hline 7 & 40 & 70 & 110 & 40 & -134 & 180 \\
\hline
\end{tabular}

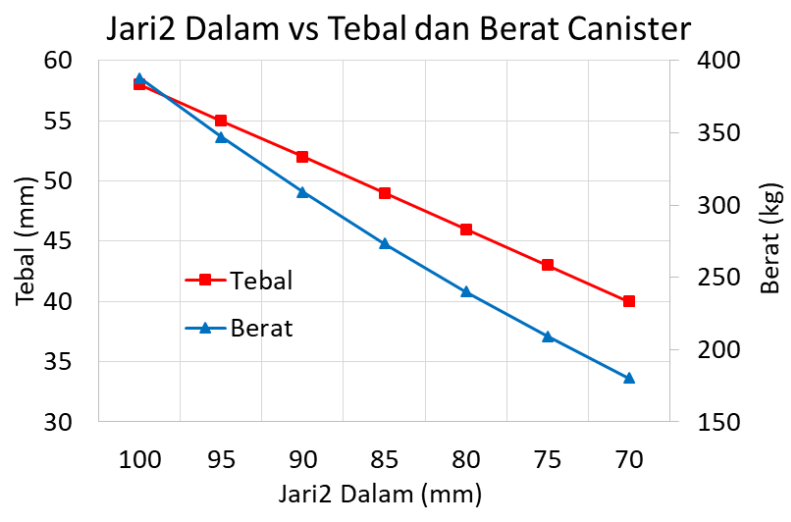

Gambar 7. Kurva Hubungan antara Jari-jari dalam canister dengan Tebal dan Berat

Jika dilihat pada kurva di atas, maka perubahan jari-jari dalam canister mempengaruhi tebal dan berat canister pada nilai tekanan $40 \mathrm{MPa}(4000$ meter kedalaman). Oleh sebab itu, disarankan rongga dalam canister diperkecil dan ini perlu re-layout dari komponen elektronik yang akan dimasukkan dalam canister, yaitu agar mempunyai dimensi lebih kecil dari jari-jari 100 $\mathrm{mm}$.

Selain analisis di atas, masih diperlukan analisis numerik untuk mengkaji deformasi yang terjadi pada struktur canister akibat tekanan luar tersebut. Analisis dilakukan pada sub-bab berikut.

\subsection{Analisis Numerik}

\subsubsection{Material Baja Antikarat (SS 316 L)}

Setelah dilakukan analisis kekuatan dan berat canister di sub-bab 3.1.1, maka perlu dilakukan analisis numerik untuk mengetahui deformasi struktur canister akibat tekanan luar. Program analisis yang digunakan adalah SAP 2000 (Computers and Structures, Inc., 2002). Program ini memerlukan data material baja (dari Tabel 1) dan dimensi-dimensi silinder yaitu jari-jari dalam silinder $\left(r_{i}\right)$ sebesar $100 \mathrm{~mm}$, tebal dinding silinder $(t)$ dipilih sebesar $34 \mathrm{~mm}$ (dari Tabel 2) dan tekanan luar sebesar $30 \mathrm{MPa}$. Nilai-nilai ini dipilih karena sesuai dengan canister yang akan dipasang di lapangan.

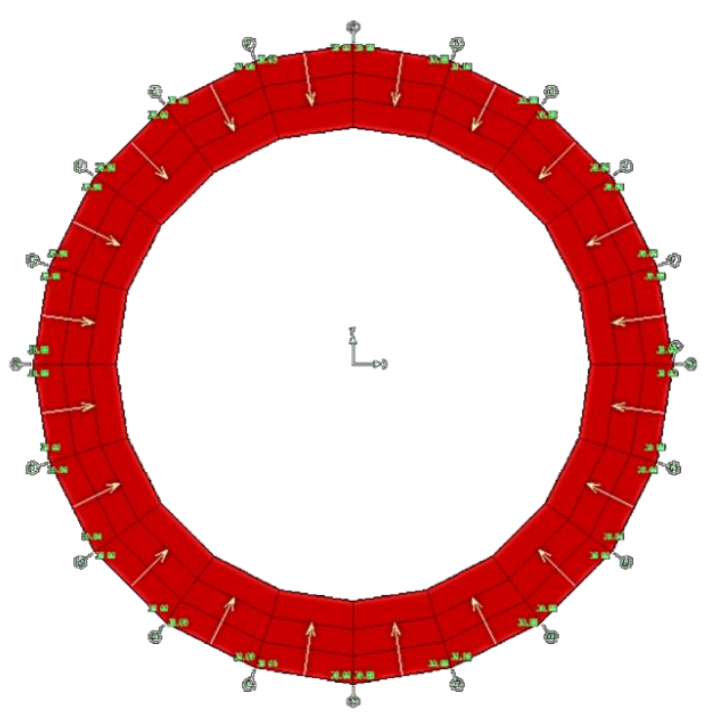

Gambar 8. Model Penampang Silinder Baja yang Dianalisis Numerik

Gambar 8 menunjukkan model penampang silinder baja yang akan dianalisis secara numerik. Setiap nodal pada model ini diberi kekangan (restraint) sehingga hanya dapat bergerak secara radial. Pada arah keliling, elemen dibagi menjadi 20 elemen hingga, sedangkan arah radial, dibagi menjadi 3 elemen hingga. Tanda panah menuju ke pusat adalah arah tekanan luar, diberi nilai sebesar $30 \mathrm{MPa}$. Hasil tegangan yang terjadi pada dinding silinder ditunjukkan pada Gambar 9. Dari distribusi tegangan tersebut, tampak bahwa pada dinding bagian dalam, tegangan yang terjadi adalah $116 \mathrm{MPa}$, sedangkan tegangan pada dinding luar adalah $71 \mathrm{MPa}$. Tegangan ini sedikit lebih kecil dibanding nilai hasil analisis eksak dengan Persamaan (2) yang sebesar $134 \mathrm{MPa}$ untuk dinding dalam. Dengan kata lain, hasil dari analisis numerik sedikit underestimated. Memang hasil numerik tidak selalu sama dengan hasil eksak, karena metode numerik adalah pendekatan dengan metode elemen hingga. Yang akan digunakan di sini adalah hasil dari analisis deformasinya. 


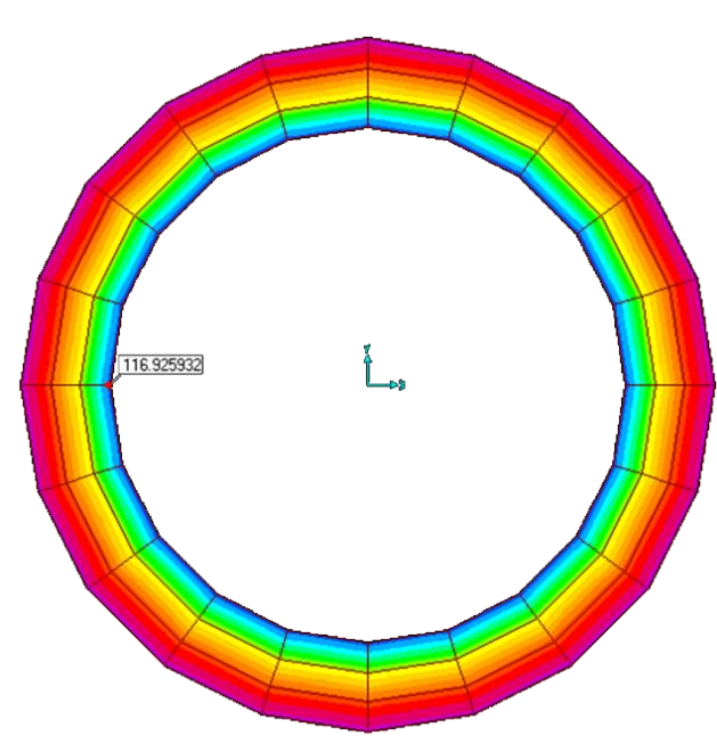

$\begin{array}{lllllllllllll}\text { 74. 77. 81. 84. 88. 91. 95. 98. 102. } 105 . & 109 . & 112 . & 116 . & 119\end{array}$

Gambar 9. Distribusi Tegangan pada Model Penampang Silinder Baja

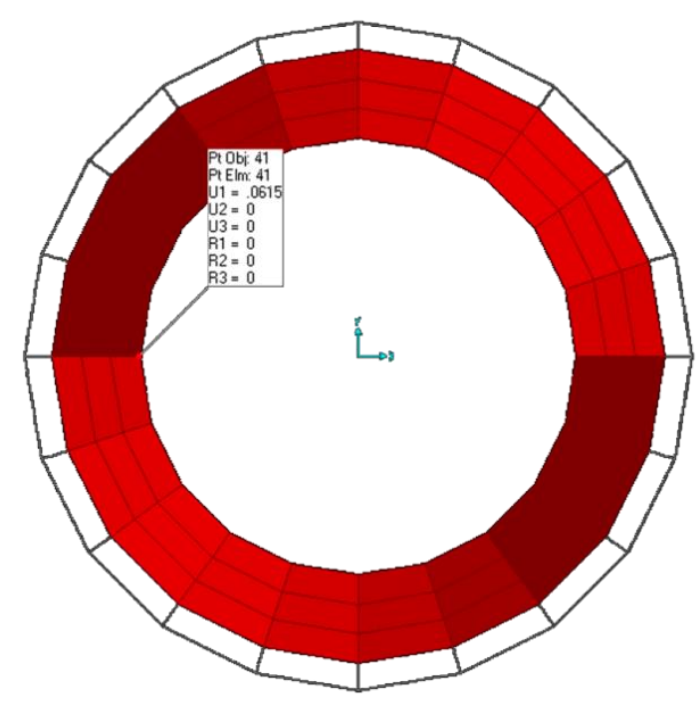

Gambar 10. Deformasi pada Model
Penampang Silinder Baja

Gambar 10 menunjukkan deformasi yang terjadi pada penampang silinder di atas. Dari Gambar 10 tampak bahwa deformasi yang terjadi adalah $0,062 \mathrm{~mm}$. Nilai ini cukup kecil dibanding dengan dimensi struktur. Pemeriksaan nilai deformasi ini penting karena berhubungan dengan potensi kebocoran, karena kalau ada bagian lain yang berdeformasi berbeda secara signifikan maka dapat terjadi potensi kebocoran.

\subsubsection{Material Titanium}

Analisis numerik untuk mengetahui deformasi struktur canister juga dilakukan untuk material Titanium. Data material juga diperoleh dari Tabel 3. Dimensi-dimensi silinder yaitu jari-jari dalam silinder $\left(r_{i}\right)$ sebesar $100 \mathrm{~mm}$, tebal dinding silinder $(t)$ dipilih sebesar 17,2 mm (dari Tabel 4) dan tekanan luar sebesar $60 \mathrm{MPa}$. Nilai-nilai ini dipilih karena sesuai dengan canister yang akan dipasang di lapangan.

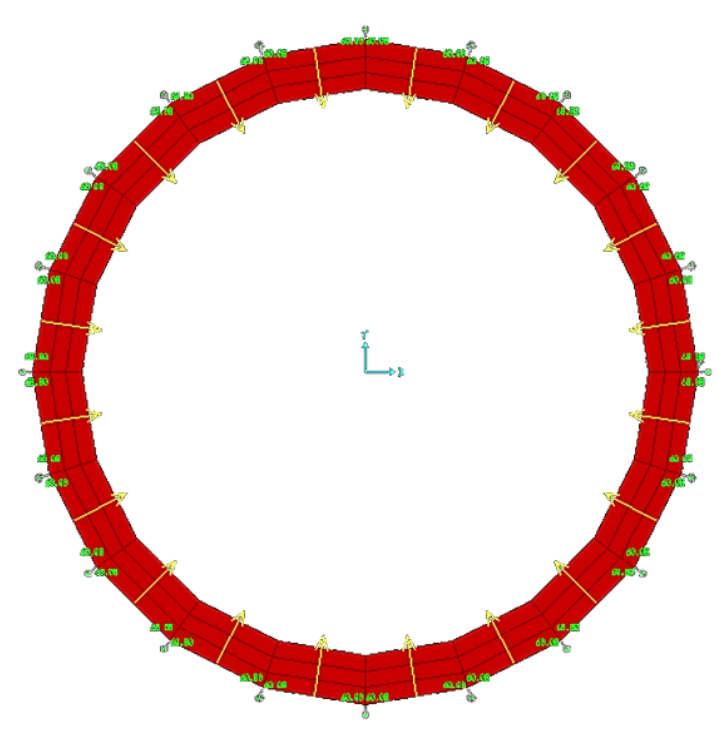

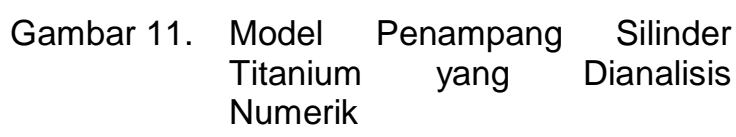

Gambar 11 menunjukkan model penampang silinder Titanium yang dianalisis secara numerik. Setiap nodal pada model ini diberi kekangan (restraint) sehingga hanya dapat bergerak secara radial. Pada arah keliling, elemen dibagi menjadi 20 elemen hingga, sedangkan arah radial, dibagi menjadi 3 elemen hingga. Tanda panah menuju ke pusat adalah arah tekanan luar, diberi nilai sebesar $60 \mathrm{MPa}$. Hasil tegangan yang terjadi pada dinding silinder ditunjukkan pada Gambar 12.

Dari distribusi tegangan tersebut, tampak bahwa pada dinding bagian dalam, tegangan yang terjadi adalah $385 \mathrm{MPa}$, sedangkan tegangan pada dinding luar adalah $294 \mathrm{MPa}$. Tegangan ini sedikit lebih kecil dibanding nilai hasil analisis eksak dengan Persamaan (2) yang sebesar $441 \mathrm{MPa}$ untuk dinding dalam. Dengan kata lain, hasil dari analisis numerik sedikit underestimated. Memang hasil numerik tidak selalu sama dengan hasil eksak, karena metode numerik adalah pendekatan dengan metode elemen hingga. Yang akan digunakan di sini adalah hasil dari analisis deformasinya. 


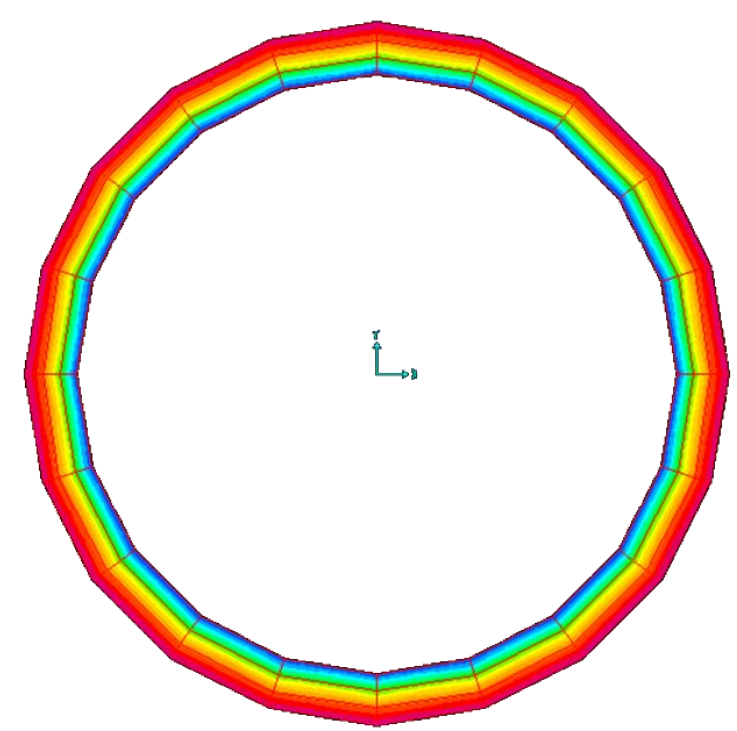

294. 301. 308. 315. 322. 329. 336. 343. 350. 357. 364. 371. 378. 365

Gambar 12. Distribusi Tegangan pada Model Penampang Silinder Titanium

Gambar 13 menunjukkan deformasi yang terjadi pada penampang silinder di atas.

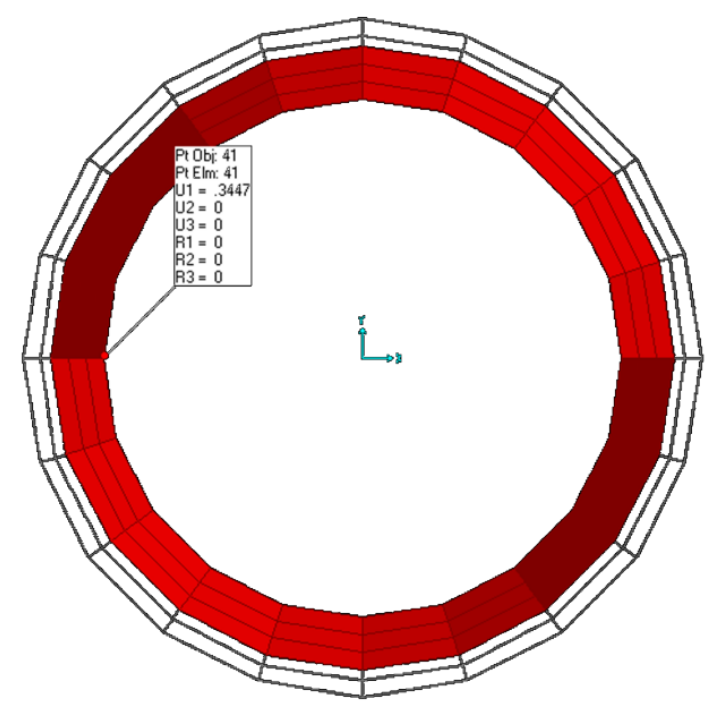

Gambar 13. Deformasi pada Model Penampang Silinder Titanium

Dari Gambar 13 tampak bahwa deformasi yang terjadi adalah $0,345 \mathrm{~mm}$. Nilai ini relatif lebih besar dibanding nilai canister berbahan baja antikarat. Dengan demikian penggunaan material Titanium harus lebih memperhatikan potensi kebocoran, dibanding penggunaan material baja antikarat.

\section{KESIMPULAN}

Telah dilakukan kajian mengenai metode kaji cepat desain canister Ina-CBT. Hasilnya menunjukkan bahwa metode ini sangat berguna untuk mengetahui secara cepat dimensi dan berat awal canister akibat beban tekanan luar dari air laut.

Dengan material baja antikarat SS $316 \mathrm{~L}$ dan jari-jari dalam canister sebesar $100 \mathrm{~mm}$, maka canister akan layak desain untuk tekanan luar sampai dengan $30 \mathrm{MPa}$ (setara 3000 meter kedalaman air laut) saja. Pada kondisi ini, tebal canister adalah $34 \mathrm{~mm}$ dan beratnya adalah $202 \mathrm{~kg}$. Deformasi dinding canister yang terjadi adalah $0,062 \mathrm{~mm}$.

Untuk tekanan di atas $30 \mathrm{MPa}$, maka tebal dan berat canister menjadi terlalu besar. Untuk tekanan $60 \mathrm{MPa}$, tebalnya mencapai $212 \mathrm{~mm}$ dan beratnya mencapai $2615 \mathrm{~kg}$. Suatu nilai yang sangat besar. Sebagai alternatif, jari-jari dalam dapat dikecilkan. Sehingga dilakukan kaji sensitifitas pengecilan jari-jari. Namun demikian, pengecilan ini dibatasi oleh besarnya komponen elektronik yang bisa masuk ke dalam rongga canister.

Sebagai alternatif dapat digunakan material Titanium yang lebih unggul dari segi sifat fisik dan mekanik. Hasilnya menunjukkan untuk tekanan sampai dengan $60 \mathrm{MPa}(6000$ meter kedalaman air), tebal canister hanya $17,2 \mathrm{~mm}$ dan beratnya hanya $52 \mathrm{~kg}$. Akan tetapi, karena dimensi yang kecil dan tekanan yang besar, maka deformasi dinding canister mencapai 0,345 mm. Nilai ini perlu diperhatikan untuk mencegah kebocoran.

Dengan melihat hasil-hasil ini, metode ini sangat membantu memberikan gambaran awal mengenai pengaruh parameterparameter yang dimasukkan dalam tahap desain awal. Setelah desain awal didapat, maka dapat dilanjutkan pada desain detil menggunakan perangkat lunak yang lebih teliti.

\section{PERSANTUNAN}

Ucapan terima kasih disampaikan kepada rekan-rekan B2TKS (Balai Besar Teknologi Kekuatan Struktur) BPPT di mana penulis banyak berdiskusi tentang desain kekuatan canister yang diperlukan dan kepada Kepala Program InaTEWS di PTRRB (Pusat Teknologi Reduksi Risiko Bencana) di mana kaji cepat ini digunakan untuk mencapai sasaran kinerja Program InaTEWS tersebut.

\section{DAFTAR PUSTAKA}

Ansys. 2020. Next-Generation Pervasive Engineering Simulation. [terhubung berkala]. https://www.ansys.com/ [1 Juli 2020] 
ASTM International. 2015. ASTM A240 Grade 316L Heat-Treated. 116p.

Badan Standardisasi Nasional. 2012. SNI 7840-2012 Baja Tahan Karat (Stainless Steel) Canai Dingin Bentuk Lembaran dan Gulungan (Bj TK D). 18p.

BPPT. 2020a. Laporan Desk Top Study Indonesia Cable Based Tsunameter (Ina CBT) Labuan Bajo, Nusa Tenggara Timur. 110p.

BPPT. 2020b. Laporan Detail Engineering Design (DED). Indonesia Cable Based Tsunameter (Ina CBT) Labuan Bajo, Nusa Tenggara Timur. 98p.

BPPT. 2019a. Grand Design Ina-TEWS BPPT 2019-2024. Badan Pengkajian dan Penerapan Teknologi. Tahun Anggaran 2019.

BPPT. 2019b. Laporan Pra-Feasibility Study Program Ina-TEWS. Badan Pengkajian dan Penerapan Teknologi. Tahun Anggaran 2019.

Computers and Structures, Inc. 2014. SAP2000 Linear and Nonlinear Static and Dynamic Analysis and Design of Three-Dimensional Structures, Advanced 14.0.0.

KemenkumHAM. 2019. Penguatan dan Pengembangan Sistem Informasi Gempa Bumi dan Peringatan Dini Tsunami. Kementerian Hukum dan Hak Asasi Manusia. Lembaran Negara Republik Indonesia tahun 2019 Nomor 266.

The Engineering Toolbox. 2020. Stress in Thick-Walled Cylinders. [terhubung berkala].

https://www.engineeringtoolbox.com/stress -thick-walled-tube-d_949.html [8 Juli 2020] 